\title{
Surface Temperatures in Dry Friction and Boundary Lubrication*
}

\author{
by Toshio Sakurai**, Heihachiro Okabe** and A. Sethuramiah**
}

\begin{abstract}
Summary: Surface temperatures were measured by dynamic thermocouple technique. In dry friction the temperatures were in reasonable agreement with theory as proposed by Jaegar. When lubricants are used the behavior was very much a function of the lubricant. With some lubricants the temperatures can be obtained by extending the dry friction theory and assuming that the temperature rise observed is essentially due to the metal contact. When reaction films are involved, Rehbinder effect with the consequent reduction in plastic strength appears to be a possibility.
\end{abstract}

\section{Introduction}

It is widely recognized that surface temperatures generated due to friction play an important role in lubrication and wear. Theoretical equations are available to predict surface temperatures in dry friction. However, the applicability of these equations is neither proved nor disproved experimentally in a convincing manner. The situation in boundary lubrication is more complex and very little is known about the exact surface temperatures in boundary conditions. Qualitatively the importance of surface temperatures is well recognized particularly under severe conditions. But, we cannot estimate the surface temperatures quantitatively with reasonable confidence. The present work is an attempt to understand the nature of surface temperatures in dry friction and boundary lubrication utilizing the known technique of dynamic thermocouple. Part 1 of this work refers to the studies in dry friction while Part 2 refers to the studies with lubricants. The work in Part 2 is incomplete but the available data point to some interesting conclusions and are presented.

\section{Surface Temperatures In Dry Friction}

\subsection{Experimental}

\subsubsection{Contact Geometry}

Most of the experiments were conducted with line contact. Steel disk of $4.53 \mathrm{~cm}$ diameter with an outer ring of $1 \mathrm{~mm}$ width was slid on constantan pin of $3 \mathrm{~mm}$ dia. The steel disk was made of 0.55 carbon steel. The width of contact was $1 \mathrm{~mm}$. Some experiments were also conducted with $2 \mathrm{~mm}$ wide steel disk on the flat surface of the constantan pin mainly to

* Received October 19, 1970.

** Tokyo Institute of Technology (12-1, Ookayama, Meguro-ku, Tokyo, Japan) see the effect of contact geometry.

\subsubsection{Surface Preparation}

The steel disk was prepared by hand grinding on \# 1500 emery paper. The disk was then cleaned in Soxlet apparatus for at least 2 hours under benzene reflux. The disk was later dried in a stream of dry air for 2 hours. Constantan as received was a rod of $3.2 \mathrm{~mm}$ diameter. This was machined to $3 \mathrm{~mm}$. The test pieces of $15 \mathrm{~mm}$ length were then cut. The test pieces were then cleaned in Soxlet and dried as in the case of the steel disk.

\subsubsection{Apparatus}

The friction machine utilized was a pin-ondisk friction machine and is illustrated in Fig. 1.

A threaded mild steel rod was connected to the rotating shaft through a nut. This rod rotated in mercury. A stationary mild steel rod dipping in the mercury was connected to one lead of the recorder. The test piece holder was insulated

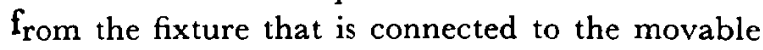
arm of the machine. Calibration of the thermocouple through the mercury switch was 0.023 $\mathrm{mV} /{ }^{\circ} \mathrm{C}$. The calibration was carried out by means of hot oil bath. Cold junction compensation was not provided as the temperature rise was quite high $\left(30 \sim 200^{\circ} \mathrm{C}\right)$ and minor correc-

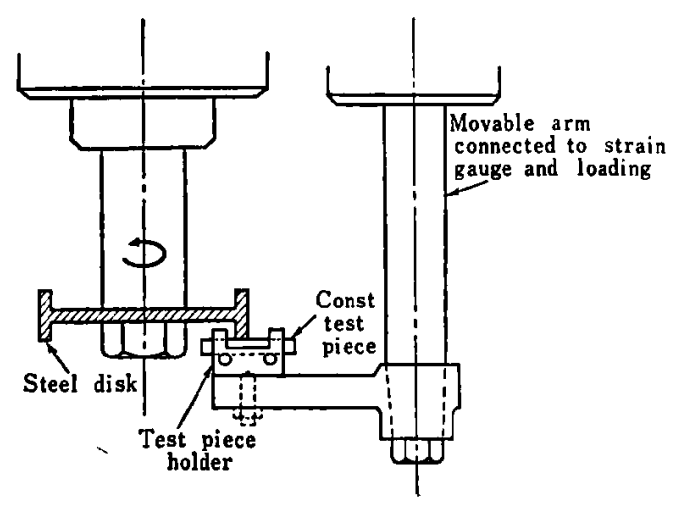

Fig. 1 Sketch of the Machine

Volume 13, No. 1, May 1971 


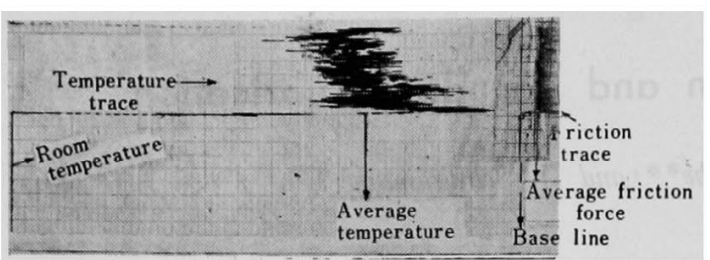

Average friction force corresponds to the average of the dark portion of the trace. The above trace is at $172 \mathrm{rpm}$ at a load of $0.5 \mathrm{~kg}$. Average temperature rise: $55^{\circ} \mathrm{C}$ and average friction force: $250 \mathrm{~g}$.

Fig. 2 Example of Temperatures Trace and Corresponding Friction Force Trace

tions do not affect the results significantly. Cold junction compensation was however provided for the studies with lubricants where relatively low temperatures were observed. The recorder utilized was YEW laboratory recorder of type LER-12. The temperature was obtained by initially setting the recorder to zero (zero corresponding to room temperature) and then converting the potential increase to temperature. Loads employed were normally $100 \mathrm{~g}$ to $1,000 \mathrm{~g}$ and four sliding speeds of $111 \mathrm{~cm} / \mathrm{sec}, 61.5 \mathrm{~cm} / \mathrm{sec}$, $40.75 \mathrm{~cm} / \mathrm{sec}$ and $19 \mathrm{~cm} / \mathrm{sec}$ (corresponding to $470 \mathrm{rpm}, 260 \mathrm{rpm}, 172 \mathrm{rpm}$, and $82 \mathrm{rpm}$ ) were utilized. The friction force was measured by means of a strain gauge, the signal from which was amplified and continuously recorded. Average temperatures were always measured and correspond to the average friction force. The average surface temperature corresponds to the center of temperature trace. Fig. 2 gives an example of temperature and friction trace.

\subsubsection{Theoretical Considerations}

The theory developed by Jaegar (1) can be used to predict the maximum as well as average temperatures generated. With the equipment used, it was felt that most probably the recorder senses the average temperatures and so the equations developed for predicting average temperatures were used. Flash temperatures occur even at light loads as clearly shown by Bowden (2) and other workers. However, it is not clear whether flash temperatures or the average temperatures effectively govern the sliding behavior. It is probable that the behavior of lubricants may be related essentially to the average temperatures.

Jaegar had developed detailed equations for band and square sources of heat. For the case of a square ( $4 l^{2}$ area) protruberance of a semiinfinite substance 2 sliding on a semi-infinite substance 1, Jaegar derived the following equ- ation for low speed condition:

$$
\lrcorner \theta_{a v}=\text { Average surface temperature rise }=\frac{0.946 q l}{\left(k_{1}+k_{2}\right)}
$$

where $q$ is the heat generated per unit area per second $\left(\mathrm{cal} / \mathrm{sec} \cdot \mathrm{cm}^{2}\right)$,

$k_{1}$ is the thermal conductivity of substance $1, \mathrm{cal} / \mathrm{cm}^{\circ} \mathrm{C} \cdot \mathrm{sec}$,

$k_{2}$ is the thermal conductivity of substance 2 , $l=$ Contact length, $\mathrm{cm}$.

The above equation is valid for low values of $L(L=V l / 2 x$ where $V$ is the velocity in $\mathrm{cm} / \mathrm{sec}$, $l$ is the contact length in $\mathrm{cm}$ and $x$ is the thermal diffusivity in $\mathrm{cm}^{2} / \mathrm{sec}$ ). But, this equation may be considered roughly valid for higher values of $L$ also. For $L$ values between 0.1 and 5 Fig. 7 of Jaegar's paper (1) may be utilized and for values of $L>5$ high speed equation derived in the same paper may be used to obtain the temperature due to moving source. For stationary source the temperature may be obtained from $\Delta \theta_{s}=\left(0.946 q^{\prime} l / k\right)$ where $q^{\prime}$ is the amount of heat flowing to the stationary source and $k$ the thermal conductivity.

As suggested by Archard (3) the temperature rise may be calculated from:

$$
\Delta \theta_{a v}=\frac{1}{\frac{1}{J \theta_{s}}+\frac{1}{J \theta_{m}}}
$$

where $\Delta \theta_{s}$ and $\Delta \theta_{m}$ are the temperature rises obtained assuming all the heat is flowing to the stationary and moving sources respectively.

A comparison between experimental temperatures observed and the theoretical values obtained utilizing Equation (1) is made in this paper. The line contact may be considered band type contact for calculation purposes at the start of a run. However the rate of wear was very high and experimentally it was clearly observed that the temperature rise was independent of apparent area. This suggested that the temperature may be effectively related to the real contact area only. The value of $l$ was calculated on the basis of square contact of $4 l^{2}$, the area being obtained on the basis of plastic yield criterion. $l$ may not be considered as the real contact length. Recent studies into the real nature of contacts $(4,5)$ indicate that with increasing loads the number of micro-contacts increase while their size tends to be effectively constant. The average temperatures developed should be governed by the contact length (which changes little with load) and the number and distribution 
of micro-contacts. Thus the situation is quite complex and $l$ based on simple square contact may at best be considered a possible dimension of length that may satisfy the overall Equation (1).

Another point to be considered is the real area of contact itself. Real area is normally obtained from plastic yield criterion. Tabor (6) pointed out the possibility of growth of contact area. While this possibility is considered in detail for static situations its applicability under dynamic conditions is open to question. The following plastic growth criterion was used in this work and is similar to the criterion proposed by Rowe (7) namely,

$$
p=\frac{p_{m}}{\left(1+3 f^{2}\right)^{1 / 2}}
$$

where $p$ is the plastic yield pressure taking into account the growth of contact area, $p_{m}$ is the static yield pressure, and $f$ is the dynamic coefficient of friction. It may be pointed out that the above criterion gave better correlation and is the only justification for using this criterion. From the above equation it follows:

$$
A_{p}=A_{\tau}\left(1+3 f^{2}\right)^{1 / 2}
$$

where $A_{\tau}$ is the real area based on static yield pressure and $A_{p}$ is the real area based on plastic growth.

$$
\begin{aligned}
& \text { Now, reconsidering Equation (1), } \\
& \begin{aligned}
\lrcorner \theta_{a v} & =\frac{0.946 q l}{\left(k_{1}+k_{2}\right)}=\frac{Q}{A_{p}} \times \sqrt{A_{p}} \times \frac{0.946}{\left(k_{1}+k_{2}\right)} \\
& =\frac{0.946 Q}{2 \sqrt{A_{p}}\left(k_{1}+k_{2}\right)}
\end{aligned}
\end{aligned}
$$

where $Q$ is the heat generated, cal/sec. $Q$ may be obtained from $Q=f W g V / J$,

where

$$
\begin{aligned}
f= & \text { coefficient of friction, } \\
W= & \text { applied load }(\mathrm{g}), \\
V= & \text { sliding speed } \mathrm{cm} / \mathrm{sec}, \\
g= & \text { acceleration due to gravity }\left(980 \mathrm{~cm} / \mathrm{sec}^{2}\right), \\
J= & \text { mechanical equivalent of heat }(4.18 \times \\
& 10^{7} \text { Joules/cal). }
\end{aligned}
$$

Equation (5) is used to calculate the theoretical temperatures. Further rearrangement of the equation substituting for $\Delta \theta$ gives,

$$
\begin{aligned}
\Delta \theta_{a v} & =\frac{0.946 f W g V}{2 J \sqrt{A_{r}}\left(1+3 f^{2}\right)^{1 / 4}\left(k_{1}+k_{2}\right)} \\
& =\frac{0.946 f V \bar{W} V \overline{p_{m}} g V}{2 J\left(1+3 f^{2}\right)^{1 / 4}\left(k_{1}+k_{2}\right)}=\frac{C V f V \bar{W}}{\left(1+3 f^{2}\right)^{1 / 4}}
\end{aligned}
$$

Where $C$ is a constant. Comparison of theoretical and experimental temperatures was attempted as a function of $V \bar{W} V f /\left(1+3 f^{2}\right)^{1 / 4}$. Some cal-
Table 1

\begin{tabular}{l|l|l|l}
\hline \multicolumn{1}{c|}{ Property } & Steel & Constantan & \multicolumn{1}{c|}{ Unit } \\
\hline Thermal Conductivity $k$ & 0.15 & 0.055 & $\mathrm{cal} / \mathrm{cm}^{\circ} \mathrm{C}$ \\
Specific Heat $c$ & 0.100 & $\mathbf{0 . 0 9 7 5}$ & $\mathrm{cal} / \mathrm{gm}^{\circ} \mathrm{C}$ \\
Density $\rho$ & 7.86 & $\mathbf{8 . 9}$ & $\mathrm{g} / \mathrm{cm}^{3}$ \\
Thermal Diffusivity $x$ & $\mathbf{0 . 1 8 2}$ & $\mathbf{0 . 0 6 3 3}$ & $\mathrm{cm}^{2} / \mathrm{sec}$ \\
Flow Pressure, $p_{m}^{*}$ & - & $4.73 \times 10^{6}$ & $\mathrm{~g} / \mathrm{cm}^{2}$ \\
\hline
\end{tabular}

* Value obtained from experimental determination in tension test.

culations were also carried out taking speed effects ( $L$ factor) into consideration. These values were also compared with experimental values. It may be mentioned here that the above treatment neglects the changes in the properties of the substances with temperature. The material constants used are summarized in Table 1 above. 1.1.5 Discussion of Experimental and Theoretical Results

Normally each experiment was run for 1/2 minute. The wear rate was observed to be very high $\left(0.04\right.$ to $1.5 \mathrm{~mm}^{3} /$ minute). The wear track was always found grooved. The average friction coefficient was normally between 0.5 and 1.0 for line contact. For flat contact the coefficient was lower $(<0.5)$. It was observed in all experiments that the average surface temperature is essentially independent of the apparent area. This was further confirmed by running some experiments for as long as five minutes. This is in agreement with the observation of Furey (8) who also studied surface temperatures utilizing dynamic thermocouple. From Equation (6) the theoretical temperatures were calculated. The values of $f V V W /\left(1+3 f^{2}\right)^{1 / 4}$ corresponding to the experimental temperature rise are then calculated for $82,172,260$, and 470 rpm, and compared with the theoretical tempe-

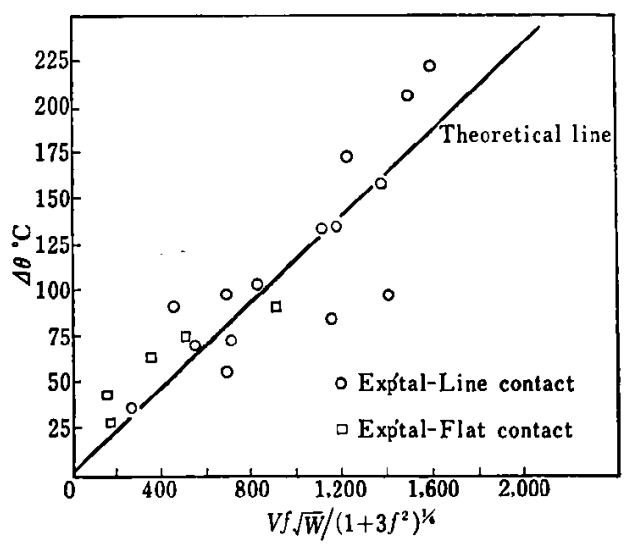

Fig. 3 Surface Temperature Rise vs. $\frac{V f V \bar{W}}{\left(1+3 f^{2}\right)^{1 / 4}}$ at $470 \mathrm{rpm}$ 


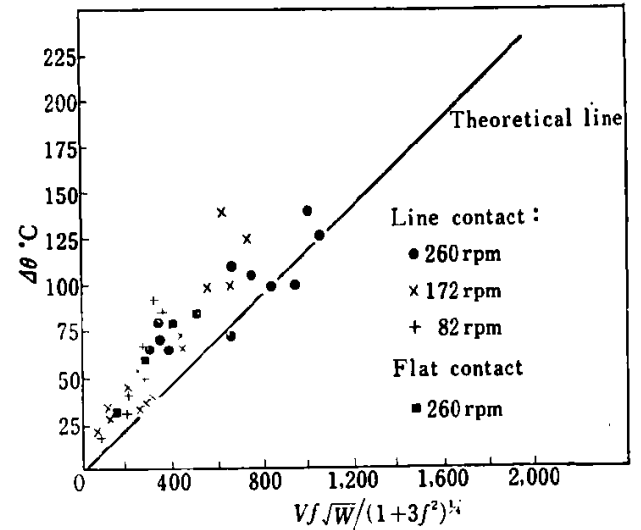

Fig. 4 Surface Temperature Rise vs. $\frac{V f V \bar{W}}{\left(1+3 f^{2}\right)^{1 / 4}}$ at 82,172 and $260 \mathrm{rpm}$

ratures in Fig. 3 and 4.

The values at $470 \mathrm{rpm}$ are plotted in Fig. 3 whereas the values at other speeds are plotted in Fig. 4. From these figures it may be observed that the agreement is generally within $\pm 30^{\circ} \mathrm{C}$. The results for $82 \mathrm{rpm}$ seem to deviate more than other results. The results in Fig. 4 include some data obtained with flat contact also. The agreement appears to be better at higher temperatures. In this connection it may be pointed that the determination of average friction force may involve some error as it was very difficult to estimate average force correctly when the fluctuations of friction force were rapid. The agreement observed was considered adequate considering the random nature of the process and the possible errors in friction force measurement. Some sample calculations of exact theoretical temperatures based on a square of $4 l^{2}$ and taking into account the $L$ factor were done and are summarized in Table 2 . It may be seen from this table that the agreement is poorer, the exact theoretical temperatures being considerably lower than experimental values. Some exact calculations were also done assuming band con- tact. These temperatures were found to be still and are not tabulated.

It was thus felt that the simple Equation (1) which ignores the speed effects gives the best correlation. A further test of this equation was attempted with Furey's data (8) where spherical contact geometry was used. The situation was as bad as observed by Furey and wide disagreement was found between theoretical and his experimental values. The reasons for this disagreement are not clear. Furey seems to have used peak friction values whereas we always used average friction values. This may be the reason for the discrepancy observed. While the temperature fluctuates with friction force it does not follow the variations as rapidly and it was considered that the average temperature is more likely to correspond to the average friction force. This average friction force was the value corresponding to the darker portion of friction tracethe lighter portions of the trace being considered as the fluctuations around this relatively steady friction.

\subsection{Conclusions}

1. In general, the existing theory is adequate to predict surface temperatures in dry friction.

2. The approximate equation for surface temperature rise calculation was found to give better correlation with experimental values than the exact theory. The agreement is better at higher temperatures. It appears that this simple over-all equation may be used with reasonable confidence, at least with speeds of the same order used in this work.

3. In the simple Equation (1) $l$ is considered to be equal to $\sqrt{A_{p}} / 2$ and taken as a dimension of length capable of satisfying the equation. This holds irrespective of contact geometry (for example most of the work reported here was with line contact).

Table 2 Exact Theoretical Calculation of Surface Temperatures Based on a Square of $4 l^{2}$ Dimension

\begin{tabular}{|c|c|c|c|c|c|c|c|c|c|c|}
\hline $\begin{array}{l}\text { Speed } \\
\mathrm{cm} / \mathrm{sec}\end{array}$ & $W, \mathrm{~g}$ & $\begin{array}{c}q\left(\mathrm{cal} / \mathrm{sec} \cdot \mathrm{cm}^{2}\right) \\
\times 10^{-3}\end{array}$ & $f$ & $\begin{array}{l}l, \mathrm{~cm} \\
\times 10^{+3}\end{array}$ & $L=\frac{V l}{2 x}$ & $J \theta_{n}^{\circ} \mathrm{C}$ & $\Delta \theta_{s}^{\circ} \mathrm{C}$ & $\begin{array}{c}\Delta \theta_{a v}{ }^{\circ} \mathrm{C} \\
\text { (Theory) }\end{array}$ & $\begin{array}{c}\Delta \theta_{a v}{ }^{\circ} \mathbf{G} \\
\text { (Exp'tal) }\end{array}$ & $\begin{array}{c}\Delta \theta_{a v}{ }^{\circ} \mathrm{C} \\
\text { (Theory) } \\
\text { app. equation (1) }\end{array}$ \\
\hline $\begin{array}{l}111 \\
111 \\
111 *) \\
61.5 \\
40.7\end{array}$ & $\begin{array}{r}500 \\
300 \\
300 \\
500 \\
1,000\end{array}$ & $\begin{array}{l}5.1 \\
3.9 \\
3.14 \\
2.56 \\
1.83\end{array}$ & $\begin{array}{l}0.55 \\
0.37 \\
0.26 \\
0.55 \\
0.57\end{array}$ & $\begin{array}{l}5.9 \\
4.3 \\
4.0 \\
6.2 \\
8.6\end{array}$ & $\begin{array}{l}5.2 \\
3.9 \\
3.7 \\
3 \\
2.8\end{array}$ & $\begin{array}{r}147 \\
110 \\
87 \\
112 \\
120\end{array}$ & $\begin{array}{r}190 \\
105 \\
80 \\
100 \\
102\end{array}$ & $\begin{array}{l}83 \\
53 \\
42 \\
52 \\
55\end{array}$ & $\begin{array}{r}135 \\
73 \\
75 \\
72 \\
100\end{array}$ & $\begin{array}{r}139 \\
77 \\
59 \\
73 \\
75\end{array}$ \\
\hline
\end{tabular}

Note:

1) Constantan receives heat from a moving source and $\Delta \theta_{m}$ is the temperature obtained assuming all heat flowing to constantan from Fig. 7 of Jaegar's papcr (1).

2) Steel disk receives heat from stationary source and $\Delta \theta_{s}=0.946 q l / K$ assuming all heat flowing to steel.

*) Result with flat contact. All the other results refer to line contact. 
4. The surface temperature rise is found to be independent of the apparent area.

\section{Surface Temperatures in Boundary Lubrication}

\subsection{Contact Geometry}

Line contact as in the case of dry friction was used. The constantan pin of $3.2 \mathrm{~mm}$ in dia. was used instead of $3 \mathrm{~mm}$ and the test pieces were cut from a different rod. No machining was done on constantan rod. The constantan piece was insulated by plastic bushes from the test piece holder.

\subsection{Apparatus}

Apparatus used was essentially the same as for dry friction studies. However, in view of the relatively low temperatures developed ice point was used for better accuracy. The electrical circuit used is given in Fig. 5. The thermocouple calibration was found to be $0.0192 \mathrm{mV} /{ }^{\circ} \mathrm{G}$.

\subsection{Experimental Procedure}

First the recorder pointer was adjusted to zero. Then with stabilized ice point the room temperature was observed when the circuit was closed. The observed temperature from the recorder was within $\pm 1^{\circ} \mathrm{C}$ of the room temperature. The lubricant to be tested was applied by hand and the test started with $0.5 \mathrm{~kg}$ load. The lubrication throughout was by hand application of small quantities at frequent intervals. The test was run till the temperature stabilized. Then the load was increased to $1 \mathrm{~kg}$ and the test run till the temperature stabilized. Similarly the experiment was continued with 2, 3, and $4 \mathrm{~kg}$ load. The machine was not stopped during a test from $0.5 \mathrm{~kg}$ to $4 \mathrm{~kg}$. This procedure was continued at the 4 speeds of $82,172,260$ and 470

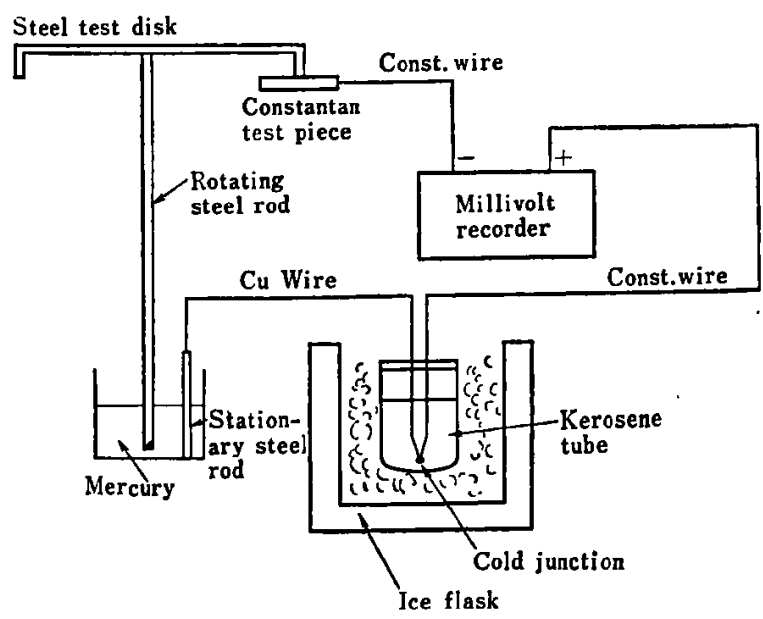

Fig. 5 Sketch of the Electrical Circuit rpm.

\subsection{Lubricants Studied}

The lubricants studied are cetane, kerosene, Sanvac oil and, Esso Crystol 70 white oil. Both the commercial oils are mineral oils. The properties of these lubricants are listed below.

Cetane:

Refractive index $n_{0}^{20}: \quad 1.4352$

Density $d_{i}^{20}: 0.7750$

m.p.: $18.1^{\circ} \mathrm{C}$

Kerosene:

Viscosity at $20^{\circ} \mathrm{C}: \quad 0.87 \mathrm{cSt}$

Refractive index $n_{\mathrm{D}}^{20}$ : $\quad 1.442$

Density $d_{6}^{20}: 0.789$

Sanvac oil:

Viscosity $100^{\circ} \mathrm{F}: 46.9 \mathrm{cSt}$

$$
210^{\circ} \mathrm{F}: 5.7 \mathrm{cSt}
$$

Refractive index $n_{\mathrm{D}}^{20}: \quad 1.497$

Density $d_{4}^{20}: 0.890$

Esso Crystol 70 white oil:

Viscosity $100^{\circ} \mathrm{F}: 14.1 \mathrm{cSt}$

$$
210^{\circ} \mathrm{F}: 3.14 \mathrm{cSt}
$$

Refractive index $n_{\mathrm{D}}^{20}: \quad 1.4619$

Density $d_{4}^{20}:^{\prime} 0.840$

\subsection{The Assumptions Involved}

It was considered that the temperature rise should be a function of metallic contact and the analysis of the data is based on this assumption.

The heat carried away by the lubricant is neglected and the bulk temperature is considered to be equal to the room temperature. Some experiments were conducted in which the lubricant application was stopped for one minute. The average temperature remained the same indicating that the heat carried away by the lubricant is negligible.

\subsection{Experimental Results and Discussion}

The behavior observed with kerosene and cetane was different from that of the Sanvac oil and white oil. Firstly, the behavior of kerosene and cetane is considered and data for the other two lubricants shall be considered later.

The typical behavior with cetane and kerosene was as follows. When $0.5 \mathrm{~kg}$ load was applied there was high friction and temperature. These values dropped to lower values in 1 or 2 seconds. The temperature then stabilized at a slightly lower value after about 1/2 minute. The temperature stabilized faster with cetane than with kerosenc. The friction coefficient was generally 0.1 to 0.15 for cetane and kerosene.

The data for kerosene and cetane were treated by two methods. In one procedure the tem- 
perature rise was plotted directly as a function of $J^{\top} V W \bar{W}$ where $f$ is the over-all friction coefficient. This is an approximate method as the temperature should depend essentially on the metallic friction and not on the over-all friction. In the other procedure metallic friction component was calculated and the temperature rise was plotted as a function of $f_{m} V V \overline{W_{1}}$ where $f_{m}$ is the metallic friction coefficient and $W_{1}$ is the load supported by metal junctions. For this purpose metallic friction coefficient of 0.2 and lubricant coefficient of 0.07 were assumed. $W_{1}$ is equal to $\alpha W^{\prime}$ where $\alpha$ is the percentage metal contact. $\alpha$ itself is obtained from the following equation due to Bowden and Tabor (2):

$$
f=f_{m}+(1-\alpha) f_{l}
$$

The factor $f /\left(1+3 f^{2}\right)^{1.1}$ is disregarded as it is $\simeq 1$ for the values of $f$ involved.

Fig. 6 and 7 compare the values with the dry friction theoretical line for cetane based on the above two procedures. Firstly, it may be ob-

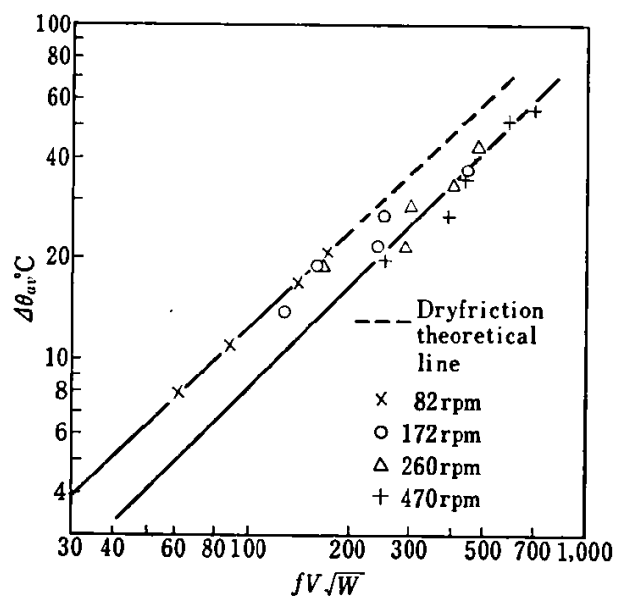

Fig. $6 f V V \bar{W}$ vs. $\lrcorner \theta_{a v}$ for Cetane

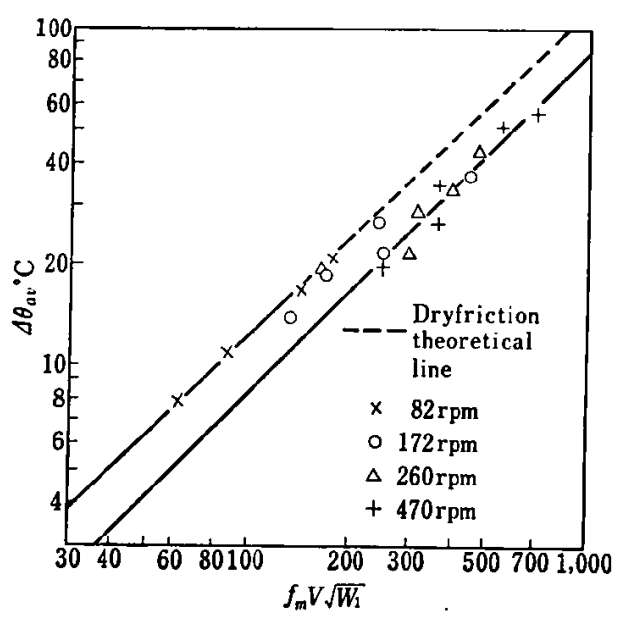

Fig. $7 f_{m} V \vee \overline{W_{1}}$ vs. $\Delta \theta_{a v}$ for Cetane served from the figures that the two procedures gave results which are very close. In this connection it may be pointed out that if higher $f_{m}$ values (of the order of 0.5 ) are assumed the correlation is much poorer, the temperatures being considerably below the theoretical line. This suggested that $f_{m}$ values may be quite close to the over-all friction coefficient. $f_{l}$ value is considered as 0.07 but it is possible that changes occur in this value. The changes in $f_{l}$ are small and for the values of $f$ involved (normally $>0.1$ ) the changes in $\alpha$ and hence $W_{1}$ will be small. The effect on $f_{m} \sqrt{W_{1}} V$ will be still smaller as this factor changes with $V \overline{W_{1}}$. The results show that the agreement with dry friction theoretical line is very close at lower temperatures. At around $20^{\circ} \mathrm{C}$ temperature rise (total temperature $\simeq 50 \mathrm{C}$ ) there is a transition in the behavior of cetane. Beyond transition the experimental values are lower than theoretical values but do fall in a straight line. This behavior is rather unusual as normally poorer lubrication and hence better agreement with theory should be expected at higher temperatures. The friction coefficient varied between 0.1 and 0.15 at all speeds except at $470 \mathrm{rpm}$. At $470 \mathrm{rpm}$ the friction coefficients were lower and varied between 0.09 and 0.11 . Hydrodynamic effects, if any, should be very minor for coefficients of this order. One possible reason for this transition is that around $50^{\circ} \mathrm{C}$ cetane undergoes some oxidation and forms reaction films on the surface. It is well recognized that ductility of metals is affected by surface active compounds and is commonly referred to as Rehbinder effect. Generally the strength of metal decreases due to the surface active compounds. Kramer (9) considers that the decrease in strength is essentially due to chemical reaction whereas most of the Russian scientists consider that the change in properties is due to physical adsorption. In the present case it is considered that beyond transition temperature the flow pressure of constantan decreases due to surface reaction films. A decrease in flow pressure decreases the constant in the equation $\Delta \theta_{a v}=$ $C f V V \bar{W} /\left(1+3 f^{2}\right)^{1 / 4}$. (The constant $C$ involves flow pressure in the numerator). From the Fig. 6 and 7 and values of $C$ before and beyond transition the decrease in yield pressure of constantan is estimated to be $35 \%$. Beyond transition the slope of the line is slightly different from the dry friction theoretical line, the experimental tem- 


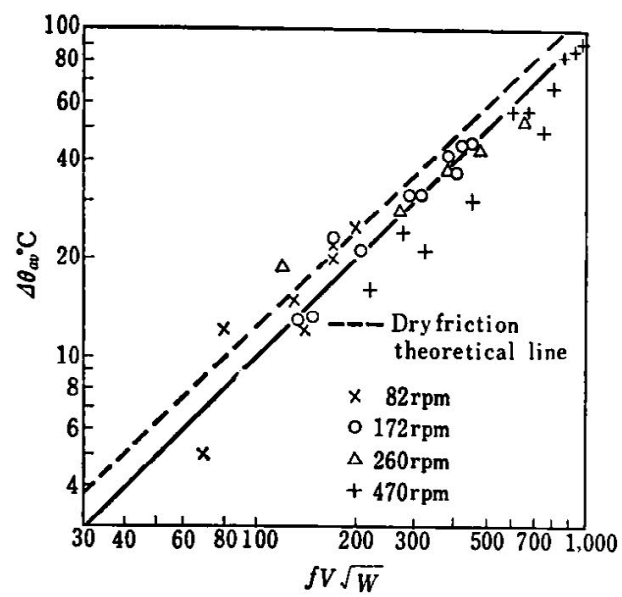

Fig. $8 f V V \bar{W}$ vs. $\Delta \theta_{c v}$ for Kerosene

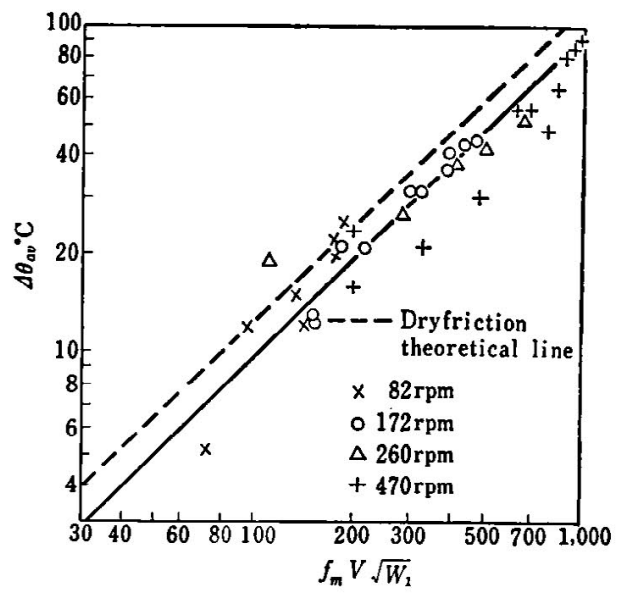

Fig. $9 f_{m} l_{1} \bar{W}_{1}$ vs. $J \theta_{a v}$ for Kerosene

peratures tending toward dry friction values. If the only change involved is the change in flow pressure, this line should be parallel. However, this is an ideal situation and the minor change in slope may be most probably due to increased film failure at higher loads. If the films fail completely it is expected that the temperature should fall on the dry friction theoretical line.

The results for kerosene are plotted as a function of $f V V \bar{W}$ and $f_{m} V V \bar{W}_{1}$ in Fig. 8 and $9 . \quad$ The same values of $f_{m}=0.2$ and $f_{1}=0.07$ were used in this case also to obtain $W_{1}$. From the figurcs it may be seen that there is no clear transition in this case. The agreement with theoretical values is quite close. The slope of the line is slightly different. Ignoring this change in slope it is estimated that reduction in yield strength is $25^{\circ}$.. for constantan. There is more scatter in the results but the trend is quite clear. The scatter may be interpreted as due to random formation of films due to impurities present in kerosene. It may also be observed that the relation ob- served in Fig. 8 and 9 is almost same.

The behavior of Sanvac oil was found to be distinctly different from kerosene and cetane. The general behavior was that with $0.5 \mathrm{~kg}$ the temperature steadily decreased with time till it went below room temperature with the friction force remaining at the same value. The fact that the temperature went below room temperature (but not zero potential as it should be for an open circuit) indicated possible formation of films with finite electrical resistance. This type of behavior was observed at $1 \mathrm{~kg}$ and $2 \mathrm{~kg}$ also. The behavior at $3 \mathrm{~kg}$ and $4 \mathrm{~kg}$ was found to be quite similar to cetane and kerosene. When there is film failure and finite steady metal contact, the metal offers least resistance and so the temperatures may be predictable by the $f_{m} V V W_{1}$ criterion. In all the studies the friction coefficient for this lubricant was very close to 0.1 . Fig. 10 and 11 show the typical temperature traces for Sanvac oil and cetane at $0.5 \mathrm{~kg}$. It may be observed also that the trace for Sanvac oil is broader.

The behavior of Esso Crystol 70 white oil was

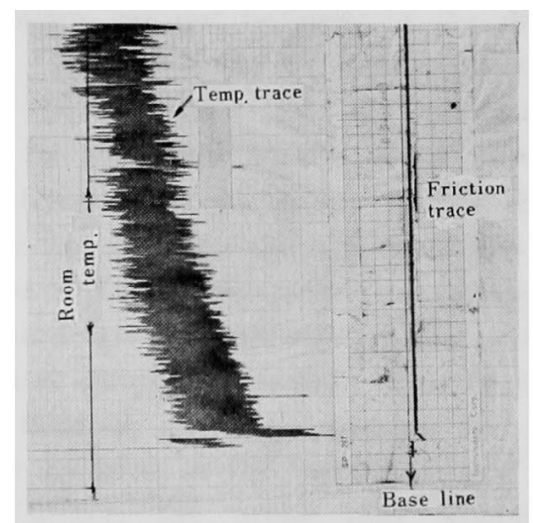

Note part of temperature trace going below room temperature while friction force is effectively constant.

Fig. 10 Temperature Trace and Corresponding Friction Trace at $0.5 \mathrm{~kg}$ and $260 \mathrm{rpm}$ for Sanvac Oil

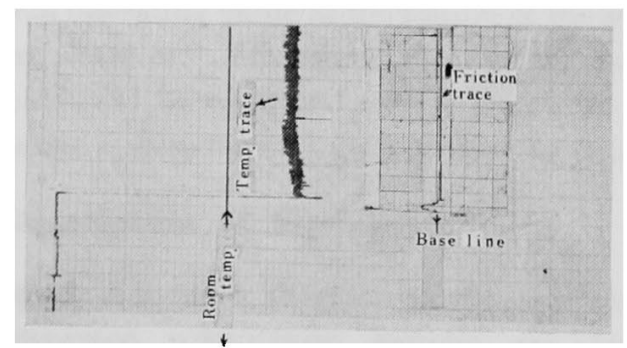

Note the steady temperature trace. Also width of trace much smaller than for Sanvac oil.

Fig. 11 Temperature Trace and Corresponding Friction Trace for Cetane at $0.5 \mathrm{~kg}$ and $172 \mathrm{rpm}$ 
not reproducible. Its behavior appeared to be between Sanvac oil and cetane. Further work is being carried out with commercial lubricants.

\subsection{Conclusions}

From the limited work carried out it is concluded that;

1. Dynamic thermocouple technique can be used for verification of the surface temperatures under boundary lubrication at least with pure hydrocarbons.

2. The temperatures remain steady for cetane and kerosene after stabilization. The temperatures are thus essentially independent of apparent area.

3. Rehbinder effect appears to be a possibility under boundary conditions and the deviation from theoretical values was explained on this basis.

4. The two commercial lubricants tested invariably involve formation of films with some finite electrical resistance and these films may effectively separate the metals at lower loads. This suggests caution is necessary whenever electrical properties of thin films are utilized as a technique.

\section{References}

1) Jaegar, J. C., "Moving Sources of Heat and the Temperature at Sliding Contacts", Proc. Royal Soc. N. S. W. 56, 203 (1942).

2) Bowden, F. P., Tabor, D., "The Friction and Lubrication of Solids", (1950) Oxford University Press, London.

3) Archard, J. F., "The Temperature of Rubbing Surfaces", Wear Vol. 2, 443, (1958/59).

4) Kragelskii, I. v., "Friction and Wear", 51 (1965) Buttersworth

5) Jones, M. H., Howells, R. I. L., Probert, S. D., "Solids in Static Contact", 225 (1968).

6) Tabor, D., "Junction Growth in Metallic Friction: The Role of Combined Stresses and Surface Contamination", Proc. Roy. Soc. A 251, 378 (1959).

7) Rowe, C. N., ASLE Trans., 9, 100 (1966).

8) Furey, M. J., ASLE Trans., 7, 133 (1964).

9) Kramer, I. R., Demer, L. J., "Effect of Environment on Mechanical Properties of Metals", Progress. in Material Science,Vol. 9, (1961) Pergamon Press 